\title{
Radiation Protection in Radiology Departments of Ahvaz University of Medical Sciences Teaching Hospitals, Ahvaz, Iran, 2015
}

\author{
Behzad Fouladi Dehaghi ${ }^{1,}$; Leila Ibrahimi Ghavamabadi ${ }^{2}$; Matare Boazar ${ }^{1}$; Kambiz Ahmadi \\ Angali ${ }^{3}$; Mehdi Noori ${ }^{1}$ \\ ${ }_{1}^{1}$ Department of Occupational Health, School of Public Health, Ahvaz Jundishapur University of Medical Sciences, Ahvaz, IR Iran \\ ${ }^{2}$ Department of Environmental Management, College of Agriculture, Ahvaz Branch, Islamic Azad University, Ahvaz, IR Iran \\ ${ }^{3}$ Department of Bio-Statistics, School of Public Health, Ahvaz Jundishapur University of Medical Sciences, Ahvaz, IR Iran \\ ${ }^{*}$ Corresponding author: Behzad Fouladi Dehaghi, Department of Occupational Health, School of Public Health, Ahvaz Jundishapur University of Medical Sciences, Ahvaz, IR Iran. Tel/ \\ Fax:+98-6113738282, E-mail: bdehaghi@gmail.com
}

Received: February 21, 2015; Revised: April 13, 2015; Accepted: April 25, 2015

\begin{abstract}
Background: Application of ionizing radiation in many fields especially in medicine is growing, and can cause adverse health effects. Objectives: The current study aimed to evaluate the radiation protection principles in radiology departments, based on national standards.

Materials and Methods: The current study was conducted in all radiology departments of the teaching hospitals in Ahvaz, Iran, and their radiation protection status was investigated using Audit technique. For this purpose Audit checklist was prepared and essential information gathered by observation, interview with radiology department managers, and documentary surveying. At the end, standard situations were classified in three levels: poor (<50\%), medium (50-75\%), and good (75-100\%).

Results: The mean of radiation protection in the studied radiology departments was 70.53\%. The highest and lowest levels of radiation protection were in quality control and suitable ventilation, respectively. Radiation protection was evaluated as medium in $71.4 \%$ and good in $28.6 \%$ of the studied radiology departments.

Conclusions: The state of observed radiation protection principles was relatively in the weak level in the studied radiology departments especially in facilities such as ventilation system, radiography entrance, and darkroom situation. More important reason was usage changing of sections as radiology billet from related organizations.
\end{abstract}

Keywords: Radiation Protection; Radiology Department, Hospital; Ionization Radiation

\section{Background}

Application of ionizing radiation is growing in many fields especially in medicine, and can cause adverse health effects. In the diagnostic imaging process, X-ray has a significant role in the healthcare and medicine in all countries (1). Several benefits of ionizing radiation usage for human well-being are quite well known to everybody. These numerous applications include new diagnostic tools to identify previously undetectable diseases, more accurate treatment and detection methods, and several improvements in health monitoring (2). On the other hand, X-ray is one of the workplace damaging factors that can cause serious defects and impacts and even incurable diseases for people who work by radiation or people referred to medical centers for diagnosis and treatment (3). Many of the interventional radiological procedures for patients also have the ability to cause internal and external patient radiation doses which are high enough to make uncertainties (4). High doses of ionizing radiation are known as main cancer inducing risk factors in the exposed patients (5). Wellknown examples and evidence supporting this fact are the carcinogenic outcomes in atomic bomb survivors of Japan. The results of the studies revealed a significant increase of cancer at doses higher than $50 \mathrm{~m} \mathrm{~Sv}$ (6). Nowadays, several employees in different job categories are exposed to ionizing radiation for the purposes of diagnostic, treatment, nuclear medicine and interventional medicine. Radiology is a fast developing field of science in which new methods and procedures are introduced continuously (7). Radiologists are exposed to low amounts of radiation $\left(1_{G Y}>\right)$ if they use individual protection tools and rules correctly, which does not have health- and life-threatening effects in short time, but may have long term effects (8). Several factors such as X-rays field non uniformed, damage of collimator, uncorresponding of lightening X-ray field, an unfavorable image presentation due to printing instruments, not to observe principals against radiation, not to use protec-

Copyright (C) 2015, Ahvaz Jundishapur University of Medical Sciences. This is an open-access article distributed under the terms of the Creative Commons Attribution-NonCommercial 4.0 International License (http://creativecommons.org/licenses/by-nc/4.0/) which permits copy and redistribute the material just in noncommercial usages, provided the original work is properly cited. 
tors for patients especially children and pregnant cause irreparable damages that are not observed by common people, and inexpert personnel (9). In order to protect the employees against occupational exposure to radiation, appropriate technical education and training suitable for effective protection of tools and equipment should be provided. These measures must be in accordance with national regulatory codes, and should be considered with ergonomic and comfort consideration for the employee to follow $(4,10,11)$.

\section{Objectives}

Due to importance of protection against ionizing radiation, the current study aimed to describe protection status against ionizing radiation in radiology departments of Ahvaz University of Medical Sciences teaching hospitals, Iran, in 2015.

\section{Materials and Methods}

The current practical and cross-sectional study was conducted by Audit method in radiology departments of all Ahvaz teaching hospitals (seven radiology departments). First the checklist was provided based on protection principles according to international organization radiation protection and Atomic Energy Organization of Iran (radiation protection criteria). These checklists consisted of two parts, facilities and procedures. Facility part consisted of nine questions about warning sings, entrance door, dimensions, ventilation, lighting, suitable darkroom, observation windows, environmental shielding, and adequate supply of personal protective equipment. Procedure part consisted of seven questions about quality control, personal protective equipment etc. checked, maintenance record, radiography room door is closed during working, personal dose monitoring, and health document and radiation safety officer. Checklist validity was confirmed by two medical physics and two medical safety experts. To complete the checklists, manager and safety officer of each center were interviewed. In the prepared checklist "zero" indicated no observance or less than 50\%, "one" average observance or up to 50\%, and "two" completely standard observance. Then, based on the levels of observance, the state of radiation protection in the radiology department was classified into three levels of poor (lower than 50\%), medium (50 - 75\%), and good (higher than $75 \%$ ).

\section{Results}

Primarily, 10 hospitals were selected for the study but due to some limitations only seven of them cooperated with the researchers. Table 1 shows the contribution rate of variables of radiation protection observances in the seven studied radiology departments. According to the observations, ventilation and quality control had minimum and maximum rates, respectively. According to the results, the weak state of ventilation and personal protective equipment etc. checked were $71.4 \%$ and $42.9 \%$ as weak state, respectively. As observed, procedure was the highest problematic parameter in all of the studied radiology departments. Figure 1 shows the implementation rate of radiation protection in the studied radiology departments, and Figure 2 shows accomplishment rate of facilities, procedures and total score for the studied radiology departments, and mean rate of facilities, procedure and total score obtained from the studied radiology departments. According to the observations facilities had the lowest score.

Table 1. Contribution Rate of Safety and Protection Compliance Variables in Radiology Department

\begin{tabular}{ll}
\hline Procedure & Facilities \\
\hline
\end{tabular}

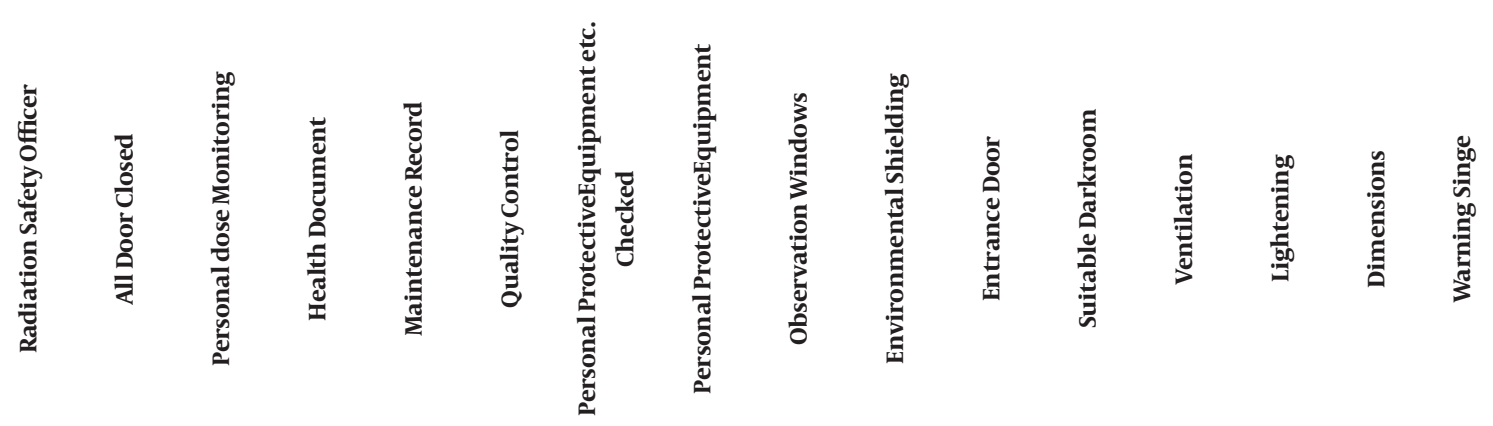

\begin{tabular}{|c|c|c|c|c|c|c|c|c|c|c|c|c|c|c|c|c|}
\hline Good & 57.1 & 14.3 & 57.1 & 57.1 & 71.4 & 71.4 & 28.6 & 57.1 & 28.6 & 42.9 & 14.3 & 14.3 & - & 28.6 & 28.6 & 28.6 \\
\hline Medium & 42.9 & 28.6 & 42.9 & 42.9 & 28.6 & 28.6 & 28.6 & 42.9 & 57.1 & 57.1 & 57.1 & 42.3 & 28.6 & 57.1 & 57.1 & 71.4 \\
\hline Poor & - & 57.1 & - & - & - & - & 42.9 & - & 14.3 & - & 28.6 & 28.6 & 71.4 & 14.3 & 14.3 & - \\
\hline
\end{tabular}


Fouladi Dehaghi B et al.

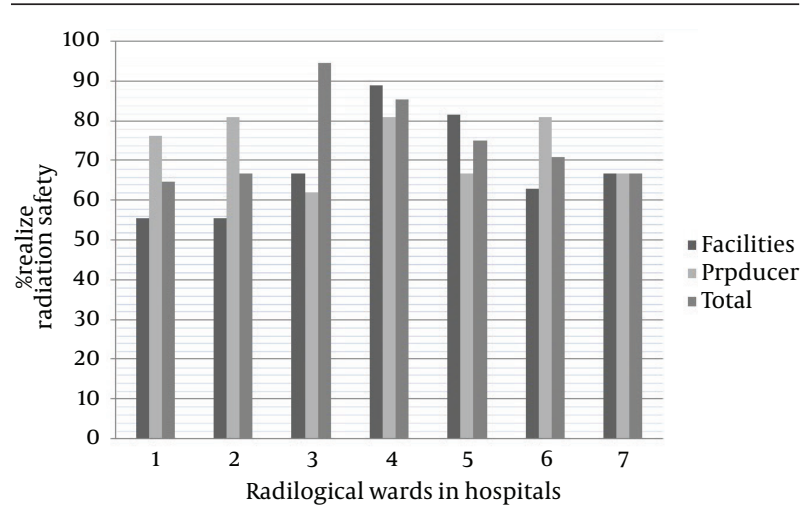

Figure 1. Implementation Rate of Radiation Safety and Protection in Radiology Departments

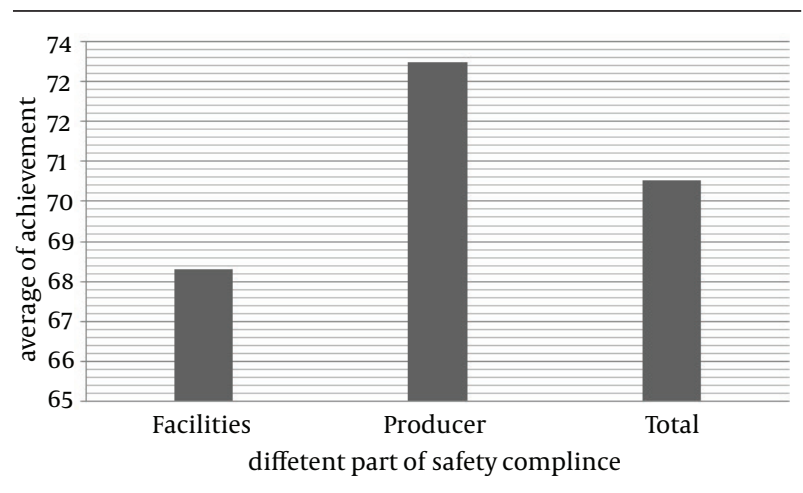

Figure 2. Mean Achievement of Safety Compliance in Radiology Department

\section{Discussion}

The current study described the situation of seven radiology departments of Ahvaz University of Medical Sciences teaching hospitals regarding radiation protection principles observation. The present study evaluated radiology departments situations in general. The results showed that $80 \%$ of the monitored departments did not have good situation especially in case of their darkrooms. The obtained results are supported by similar studies (1215). In the current study, inadequate ventilation system, inappropriate warning signs, and occurrence of light leakage were observed as important negative factors in the investigated darkrooms. These factors were also stated by Guebert and Chang $(16,17)$. According to the obtained results, $71 \%$ of the described radiology departments generally used warning signs including radiation danger posters, pregnant caution posters, and audiovisual warning signs based on national guidance for safety signs and radiation awareness of Atomic Energy Organization of Iran. Characteristics of warning signs, Patients and pregnant caution posters for radiation exposure, radiation safety notes, posters, and audio warning sign that should be switched on while the radiology instru- ment is working and producing ionization radiation (17), above mentioned factors are done by radiology staff or radiation safety authority, and it seems that they play an important role in giving warning to patients and their companions. The results showed that none of the studied radiology departments were in good conditions in case of proper ventilation. Ventilation is crucial for ionized air $\left(\mathrm{O}_{3}\right)$ during X-ray production in radiology room because of its dangers for respiratory system, the longer the radiology procedure, the more concentration of ozone (18, 19). Most of the investigated places (42.8\%) suffered from bad ventilation system design. Therefore, the produced ozone pollution will remain in the rooms and may pose the employees and the patients to a health risk. Also, the entrance doors of some of radiology departments were located in the crowded corridors and this can increase the number of people exposed to X-ray or ozone in the air. The current investigation found that only three out of the seven radiology departments were suitably designed. Thus, leading to a chance of exposure to X-ray, even to very small amounts, is still a serious concern $(20,21)$. Therefore, environmental shielding consists of architectural shielding built into the walls of the procedure room, and observation windows are especially important. The present study results showed good conditions in this regard, since $71.4 \%$ of radiology departments had proper environmental shielding. Similar to the current study, the results of Ortiz et al. showed that analysis of parameters related to quality control and corrections lead to decreasing the radiated dose to patients, which is one of the best ways to reduce exposure (22). In all of the centers, quality control is performed annually and the obtained results are recorded properly. Although patients should be exposed to radiation only shortly, the study observations showed that radiologists may face secondary dispersed radiation or lamp emissions, which is supported by Wang et al. and also Tatsumi and Tanooka $(23,24)$.

Therefore, distance and aprons are factors that have more potential effectiveness for making desirable radiation protection. The results showed that radiology departments of hospitals were in good conditions, since $85.7 \%$ of them were properly maintained regarding individual protection tools including aprons, thyroid shields and gonad shields. The obtained results also showed that lead gloves and lead glasses were not available in most radiology departments. Also, individual protection tool checkups including investigations on symptoms of worn out equipment were not performed in most radiology departments, which is a serious mishap because it has an effect on their efficiency. Individual dosimeters were only used by fulltime personal and it was not given to part time employees, while individual dosimeter rules indicated that whoever faces more than standard 10\% (500 $\mathrm{mR}$ ) should wear one $(25,26)$. According to the results of the current study, more strict supervision via several inspections is necessary for safe and authorized radiology exploitation licenses. 


\section{Acknowledgements}

The authors would like to thank all the people who cooperated in the study.

\section{Authors' Contributions}

Concepts: Behzad Fouladi Dehaghi, Leila Ibrahimi Ghavamabadi, Matare Boazar. Design: Behzad Fouladi Dehaghi, Leila Ibrahimi Ghavamabadi, Matare Boazar. Literature search: Mehdi Noori, Leila Ibrahimi Ghavamabadi, Matare Boazar. Experimental studies: Leila Ibrahimi Ghavamabadi, Matare Boazar. Data acquisition: Behzad Fouladi Dehaghi, Leila Ibrahimi Ghavamabadi, Mehdi Noori. Data analysis: Behzad Fouladi Dehaghi, Leila Ibrahimi Ghavamabadi, Matare Boazar, Mehdi Noori. Statistical analysis: Leila Ibrahimi Ghavamabadi, Kambiz Ahmadi Angali. Manuscript preparation: Behzad Fouladi Dehaghi, Leila Ibrahimi Ghavamabadi, Matare Boazar. Manuscript editing: Matare Boazar, Kambiz Ahmadi Angali, Mehdi Noori. Manuscript review: Behzad Fouladi Dehaghi, Leila Ibrahimi Ghavamabadi, Matare Boazar.

\section{Funding/Support}

The current study was granted by Ahvaz University of Medical Sciences, Ahvaz, Iran.

\section{References}

1. Johnston DA, Brennan PC. Reference dose levels for patients undergoing common diagnostic X-ray examinations in Irish hospitals. Br J Radiol. 2000;73(868):396-402.

2. Amis ES, Jr., Butler PF, Applegate KE, Birnbaum SB, Brateman LF, Hevezi JM, et al. American College of Radiology white paper on radiation dose in medicine. JAm Coll Radiol. 2007;4(5):272-84.

3. Bashore T. Fundamentals of X-ray imaging and radiation safety. Catheter Cardiovasc Interv. 2001;54(1):126-35.

4. Kim KP, Miller DL, Balter S, Kleinerman RA, Linet MS, Kwon D, et al. Occupational radiation doses to operators performing cardiac catheterization procedures. Health Phys. 2008;94(3):211-27.

5. WHO. In: Overall evaluations of carcinogenicity to humans, list of all agents evaluated to date. Cancer IAFRO, editor. 2007.

6. Pierce DA, Preston DL. Radiation-related cancer risks at low doses among atomic bomb survivors. Radiat Res. 2000;154(2):178-86.

7. Scientific Committee on the Effects of Atomic Radiation. Sources and effects of ionizing radiation: UNSCEAR 2000 report to the General Assembly, with scientific annexes. New York: United Nations; 2000.

8. Protasova OV, Maksimova IA, Cheprasov VY, Nikiforov AM. Altered balance of macroelements and trace elements in blood serum, its ultrafiltrates, and hairs long after exposure to low doses of ionizing radiation. Biology Bulletin of the Russian Academy of Sciences. 2001;28(4):344-9.

9. Simpkin DJ. A general solution to the shielding of medical $\mathrm{x}$ and gamma rays by the NCRP Report No. 49 methods. Health Phys. 1987;52(4):431-6.

10. Valentin J. Avoidance of radiation injuries from medical interventional procedures. Ann ICRP. 2000;30(2):7-67.

11. Miller DL, Vano E, Bartal G, Balter S, Dixon R, Padovani R, et al. Occupational radiation protection in interventional radiology: a joint guideline of the Cardiovascular and Interventional Radiology Society of Europe and the Society of Interventional Radiology. Cardiovasc Intervent Radiol. 2010;33(2):230-9.

12. Thrall JH. Quality and safety revolution in health care. Radiology. 2004;233(1):3-6.

13. Norozi MA, Jahangiri M, Ahmadinezhad P, Zare Derisi F. Evaluation of the safety conditions of shiraz university of medical sciences educational hospitals using safety audit technique. Payavard Salamat. 2012;6(1):42-51.

14. Mosavi SH, Faraji Khivai F, Sharifian R, Shaham G. Evalution of safety compliance in radiology department of educational hospitals of Tehran University of medical sciences. Payavard salamat Journal. 2010;3(3-4):31-7.

15. Rahimi A, Sh S. Study on the standards observance in the radiology departments of Mazandaran universities hospitals. Mazandaran university of medical sciences Journal. 2006;15(49):65-72.

16. Guebert GM, Pirtle OL, Yochum TR. Essentials of diagnostic imaging. United States: Mosby; 1995.

17. Chang PY, Doppalapudi R, Bakke J, Puey A, Lin S. Evaluation of the impact of shielding materials in radiation protection in transgenic animals. Radiat Environ Biophys. 2007;46(2):113-8.

18. Johan B, Tony P. Chesney's Radiographic Imaging. Black wolf. 1997;3.

19. ICRP. Annals of ICRP Oxford. UK: Elsevier; 1990. p. 86.Recommendations of the International Commission on Radiation Protection.

20. Cohen BL. Cancer risk from low-level radiation. AJR Am J Roentgenol. 2002;179(5):1137-43.

21. Monson R, Cleaver J, Abrams HL, Bingham E, Buffler PA Beir VII: health risks from exposure to low levels of ionizing radiation.Washington, DC: National Academies Press; 2005.

22. Ortiz P, Maccia C, Padovani R, Vano E, Carlsson G, Schibilla H. Results of the IAEA-CEC co-ordinated research programme on radiation doses in diagnostic radiology and methods for reduction. Radiation Protection Dosimetry. 1995;57(1-4):95-9.

23. Wang JX, Zhang LA, Li BX, Zhao YC, Wang ZQ, Zhang JY, et al. Cancer incidence and risk estimation among medical X-ray workers in China, 1950-1995. Health Phys. 2002;82(4):455-66.

24. Tatsumi K, Tanooka H. How to incorporate the dose-rate effect into evaluation of cancer risk for radiation protection. J Radiat Res. 2014;55(4):829-30.

25. Stanford Hospital. Radiation Protection Guidance for Hospital Staff Prepared for Stanford Hospital and Clinics, Lucile Packard Children's Hospital and Veterans Affairs Palo Alto Health Care System. California: Stanford Hospital; 2012.

26. Samerdokiene V, Mastauskas A, Atkocius V. Assessment of Annual Average Effective Dose Status in the Cohort of Medical Staff in Lithuania during 1991-2013. Radiat Prot Dosimetry. 2015. 